\title{
Bonding Analysis of Hydrogenated Lithium Clusters Using the Electron Localization Function
}

\author{
P. Fuentealba* ${ }^{* \dagger}$ and A. Savin \\ Departamento de Física, Facultad de Ciencias, Universidad de Chile, Casilla 653, Santiago de Chile, Chile, \\ and Laboratoire de Chimie Théorique, CNRS et Université Pierre et Marie Curie, Place Jussieu, \\ F-75252 Paris Cedex 05, France
}

Received: May 24, 2001; In Final Form: September 25, 2001

\begin{abstract}
The electron localization function (ELF) has been used to study the bonding characteristics of the hydrogenated lithium clusters. The analysis of the ELF clearly confirmed the hypothesis that each hydrogen atom added to the lithium cluster completely localizes one of the metallic valence electron of the cluster. Hence, the mixed clusters have a metallic part attached to a localized ionic subunit.
\end{abstract}

\section{Introduction}

In the past decade mass spectroscopy and other experimental techniques have provided measurements of the ionization potential of, among others, alkali and hydrogenated alkali metal clusters. $^{1,2}$ Theoretical calculations have given valuable information about the geometry and other properties of the mentioned clusters. ${ }^{3}$ The results are explained by the hypothesis that the bonding of one hydrogen atom localizes one of the valence electrons of the lithium cluster, and the other electrons remain delocalized. ${ }^{4}$ Very simple molecular orbital diagrams show that the more electronegative hydrogen atoms create energetically lower orbitals, explaining in this way some experimental and theoretical results. ${ }^{4,5}$ However, by doing theoretical calculations only, it is difficult to account for the localization hypothesis. It is known that the Mulliken's population analysis fails for electropositive atoms, and density or density difference plots ${ }^{2}$ do not show clear results. In this paper, we will show that the electron localization function, ELF, yields a clear picture of the electron localization due to the hydrogen bonds. As a prototype of the hydrogenated lithium clusters, the series $\mathrm{Li}_{4} \mathrm{H}_{n}(n=0-4)$, $\mathrm{Li}_{9}$, and $\mathrm{Li}_{9} \mathrm{H}$ have been studied. All of them have been experimentally detected, and some properties have been measured or theoretically calculated. ${ }^{3}$

To understand the bonding characteristics, the ELF has been used. The ELF originally proposed by Becke and Edgecombe 6 has been defined as

$$
\operatorname{ELF}(\rightarrow r)=\left[1+\left(D / D_{0}\right)^{2}\right]^{-1}
$$

where $D$ is the difference between the positive definite local kinetic energy of a system of noninteracting fermions, $t_{\mathrm{s}}(\rho)$, having the same density as the real system, and the von Weizsaecker kinetic energy density, $t_{\mathrm{w}}(\rho)$,

$$
D(\rho)=t_{\mathrm{s}}(\rho)-t_{\mathrm{w}}(\rho) \quad t_{\mathrm{w}}(\rho)=1 / 8|\nabla \rho|^{2} \rho
$$

$D_{0}$ is the local kinetic energy of an homogeneous electron gas

$$
D_{0}=c_{\mathrm{F}} \rho^{5 / 3} \quad c_{\mathrm{F}}=2.781
$$

\footnotetext{
†Universidad de Chile. E-mail: pfuentea@uchile.cl.

†NRS et Université Pierre et Marie Curie.
}

The range of values of ELF is between 0 and 1. The important term $D(\rho)$ has the physical meaning of the excess local kinetic energy density due to Pauli repulsion. ${ }^{7}$ The function ELF should demarcate the spatial regions characterizing the shared-electron interaction, as in covalent and metallic bonding, and the unshared-electron interaction such, as ionic bonding. The ELF has been extensively used to analyze a variety of bonding systems, e.g., refs 7-12. Furthermore, a topological interpretation of the ELF has been developed. ${ }^{13}$ Analyzing its gradient field, it is possible to characterize the maxima and basins. They found three types of maxima which from a chemical point of view correspond to core, bonding, and nonbonding. The volume enclosed by all the trajectories ending at a given maximum defines the basin, and the integration of the electron density over the basin gives the electron population associated with the corresponding maximum. They can be interpreted from a chemical point of view as the electron population associated with the core, bonding, and nonbonding regions. ${ }^{14}$ Note that the whole bonding analysis using the ELF does not depend on the orbitals. It could be directly calculated from the density by calculating $T_{\mathrm{s}}$ or some approximation to it. ${ }^{15,16}$

\section{Results and Discussion}

All the calculations have been done at the all-electron level using a 6-311G** basis set for all atoms and the B3LYP method of calculation. ${ }^{17}$ The geometries have been optimized and the frequencies calculated to check for possible imaginary frequencies. The electronic structure calculations have been done with the G98A.7 program $^{18}$ and the ELF has been calculated using the TopMod program ${ }^{19}$ and visualized with the vis $5 \mathrm{~d}^{20}$ software.

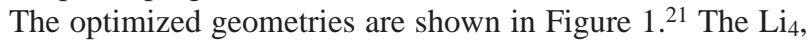
$\mathrm{Li}_{4} \mathrm{H}$, and $\mathrm{Li}_{4} \mathrm{H}_{2}$ clusters are planar whereas $\mathrm{Li}_{4} \mathrm{H}_{3}$ and $\mathrm{Li}_{4} \mathrm{H}_{4}$ are tetrahedral. Their geometries are almost identical to the ones reported in refs 2 and 3 . It is, however, interesting to mention that the $\mathrm{Li}-\mathrm{Li}$ bond distance is shorter the more hydrogen atoms the cluster has. The distance is 3.011, 2.900, 2.827, 2.548, and $2.464 \AA$ for $\mathrm{Li}_{4}, \mathrm{Li}_{4} \mathrm{H}, \mathrm{Li}_{4} \mathrm{H}_{2}, \mathrm{Li}_{4} \mathrm{H}_{3}$, and $\mathrm{Li}_{4} \mathrm{H}_{4}$, respectively. The angle between $\mathrm{Li}$ atoms also decreases along the series. It seems that the hydrogenation makes the cluster more compact. The geometry of $\mathrm{Li}_{9}$ corresponds to a slightly deformed square bypyramid similar to one of the structures reported earlier by Jones et al. ${ }^{22}$ The presence of one hydrogen atom in $\mathrm{Li}_{9} \mathrm{H}$ changes completely the geometry in comparison with $\mathrm{Li}_{9}$, as 
a)

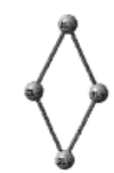

d)

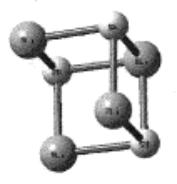

g)

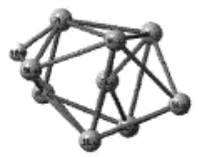

b)

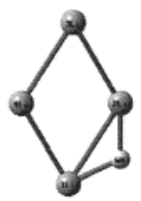

e)

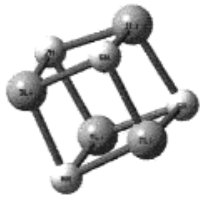

c)

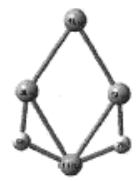

f)

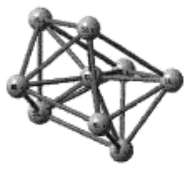

Figure 1. Geometry of the clusters, $\mathrm{Li}_{4} \mathrm{H}_{n}$ with $n=0-4$ starting from panel a until panel e. Panels $\mathrm{f}$ and $\mathrm{g}$ represent the clusters $\mathrm{Li}_{9}$ and $\mathrm{Li}_{9} \mathrm{H}$, respectively.

TABLE 1: Total Energy and Hydrogen Bonding Energy

\begin{tabular}{ccc}
\hline & $E_{\mathrm{T}}($ in au $)$ & $\Delta E^{a}$ (in kcal/mol) \\
\hline $\mathrm{Li}_{4}$ & -30.058339 & \\
$\mathrm{Li}_{4} \mathrm{H}$ & -30.672365 & 71.3 \\
$\mathrm{Li}_{4} \mathrm{H}_{2}$ & -31.306926 & 78.0 \\
$\mathrm{Li}_{4} \mathrm{H}_{3}$ & -31.931673 & 78.1 \\
$\mathrm{Li}_{4} \mathrm{H}_{4}$ & -32.573920 & 80.9 \\
$\mathrm{Li}_{9}$ & -67.706307 & 72.1 \\
$\mathrm{Li}_{9} \mathrm{H}$ & -68.321681 & \\
$a$ & $\Delta E=\left(E_{\text {tot }}\left(\mathrm{Li}_{n} \mathrm{H}_{m}\right)-n E(\mathrm{H})-E\left(\mathrm{Li}_{n}\right)\right) / m$.
\end{tabular}

can be seen in Figure 1. It may be noted that in the planar clusters with four lithium atoms the hydrogens bind always at the two lithium atoms side whereas in the three-dimensional clusters they prefer to bind at a three atom face position. In Table 1, the total energies and hydrogen bonding energies per atom are displayed. There is not a significant variation in the hydrogen bond energy along the series of clusters, which is an indication of a similar nature of the bond in all clusters.

Figure 2 shows the isosurfaces of ELF $=0.8$ for all the studied clusters. Starting with $\mathrm{Li}_{4}$, panel a, one can observe the four core basins in red (the one on the top is behind the valence basin) and two valence basins in green. The population of the core basins is $2.0 \mathrm{e}$ representing the localized core electrons. The four valence electrons are distributed between the two valence basins, each with a population of around $1.9 \mathrm{e}$. The bonding in the cluster is clearly of the two-electron-three-center type. ${ }^{7,12}$ The next picture, panel $b$, is of $\mathrm{Li}_{4} \mathrm{H}$ where the hydrogen basin at the bottom on the right has a population of 2.0e. The valence basin at the bottom on the left contains only 1.0e. At the top remains one basin with a population of $1.9 \mathrm{e}$, representing the two-electron-three-center bond. Also notable is the slight repulsion between the electrons bonding the lithium atoms on the top and the two electrons of the polarized $\mathrm{Li}-\mathrm{H}$ bond. In panel $\mathrm{c}$ one can see the ELF $=0.8$ isosurface for $\mathrm{Li}_{4} \mathrm{H}_{2}$. Now, each hydrogen basin has a population of 2.0e, and the twoelectron-three-center basin remains at the top of the figure with a population of $1.9 \mathrm{e}$. It is interesting to observe that the isosurface of $\mathrm{Li}_{4}$ explains why the hydrogen atoms prefer the position between two lithium atoms and not, for instance, an on top position. One can see that the valence electrons are localized between lithium atoms and not outside the cluster at an on top position. Note that $\mathrm{Li}_{4} \mathrm{H}_{2}$ is divided in two regions, one with delocalized electrons and one with localized electrons, as should be in a model for a metallic-insulator interphase. Note

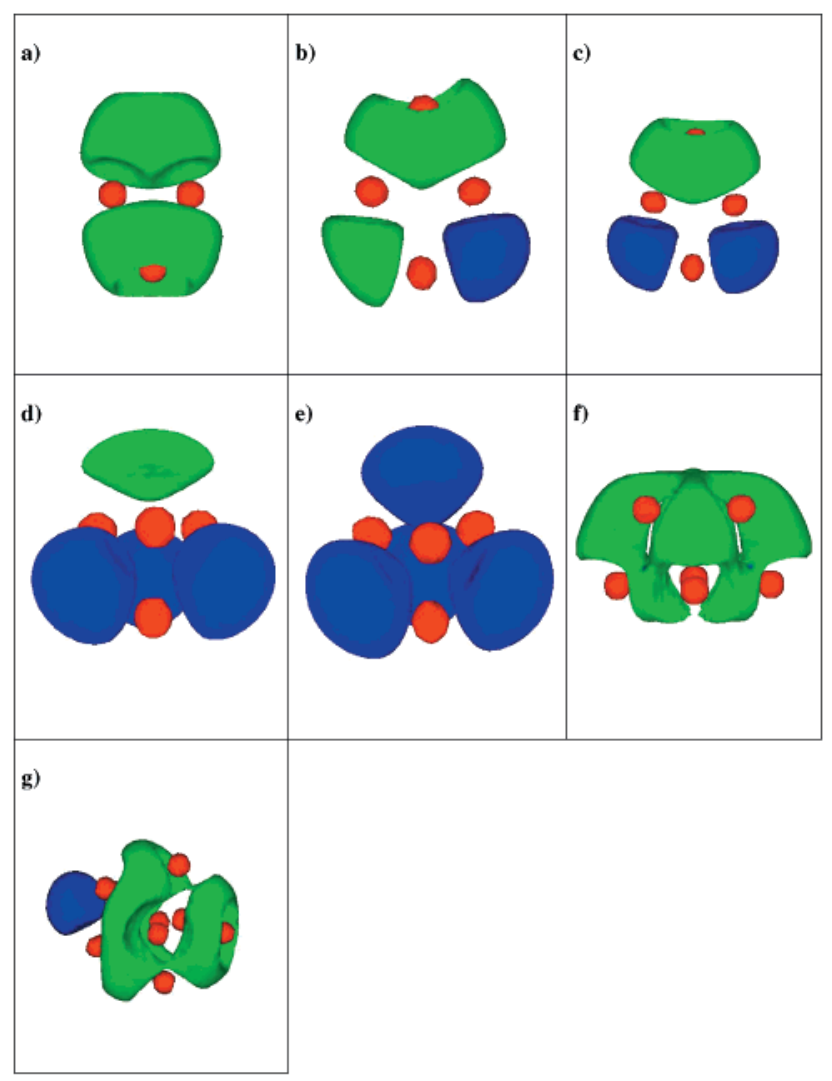

Figure 2. Isosurfaces of the electron localization function (ELF) at the value of 0.8 . The panels contain the clusters in the same order as in Figure 1.

that both hydrogen atoms are in a cis position instead of trans. In this way, the system maintains the two-electron-three-center bonding of the lithium atoms. The following two pictures, panels d and e, correspond to $\mathrm{Li}_{4} \mathrm{H}_{3}$ and $\mathrm{Li}_{4} \mathrm{H}_{4}$, respectively. The tetrahedral geometry is presented in the ELF $=0.8$ isosurfaces. The change to a three-dimensional structure can be rationalized using an ionic model. Each hydrogen atom takes one electron of the cluster, creating a positive charge on each lithium center and the electrostatic repulsion does not favor a planar geometry. Although the geometries are now completely different with respect to the already discussed ones the bonding characteristics are the same. Each hydrogen basin has associated a population of around 2.0e, and all the valence electrons are well localized. The delocalized character of the valence electron cloud of $\mathrm{Li}_{4}$ is completely lost in $\mathrm{Li}_{4} \mathrm{H}_{3}$ and $\mathrm{Li}_{4} \mathrm{H}_{4}$, where the hydrogen atoms are bonding at a 3-fold position. The last two pictures in panels $\mathrm{f}$ and $\mathrm{g}$ show the ELF $=0.8$ isosurfaces for the clusters of $\mathrm{Li}_{9}$ and $\mathrm{Li}_{9} \mathrm{H}$. The isosurface for $\mathrm{Li}_{9}$ shows a complete delocalization of the nine valence electrons around the cluster with a small charge acummulation at the top of the smaller 4-fold lithium atoms face. $\mathrm{In}_{\mathrm{Li}} \mathrm{H}$, the hydrogen bond is similar to the one found in the $\mathrm{Li}_{4} \mathrm{H}_{n}$ series of clusters. It seems that the hydrogen atom approachs one of the 3 -fold faces of the lithium cluster in the region where the valence basins are. A strong polarized bond with a basin population of 2.0e can be found at a 3 -fold position. It means, like in $\mathrm{Li}_{4} \mathrm{H}$, that the hydrogen atom in $\mathrm{Li}_{9} \mathrm{H}$ localizes one of the valence electrons of the metallic cage. To our knowledge, the laplacian of the density analysis as in the atoms in the molecules model of Bader, ${ }^{23}$ which could yield similar results, has not been applied to the mentioned clusters.

Concluding, the ELF has clearly shown the bonding characteristics of the hydrogenated lithium clusters. The bare lithium clusters have the valence electrons delocalized, as it must be 
for metallic clusters. Each hydrogen atom added to the cluster forms a very polar bond with more than one lithium atom and localizes completely one of the valence electrons of the lithium cluster. Hence the bare lithium clusters of the type $\mathrm{Li}_{n}$ have delocalized bonds, which progressively transform into those producing the metallic character of the solid, whereas the completely hydrogenated clusters of the type $\mathrm{Li}_{n} \mathrm{H}_{n}$ has bonds modeling an insulator. The clusters of the type $\mathrm{Li}_{n} \mathrm{H}_{m}$, with $n$ $>m$, depending on the cluster geometry, could model a metallic/ insulator interphase. ${ }^{24}$

Acknowledgment. Part of this work has been supported by FONDECYT (Fondo de Desarrollo Cientifico y Tecnologico), grants 1990 213, 1010 649, and 7980081.

Supporting Information Available: Tables of Cartesian coordinates for all clusters. This material is available free of charge via the Internet at http://pubs.acs.org.

\section{References and Notes}

(1) Vezin, B.; Dugourd, Ph.; Rayane, D.; Labastie, P.; Chevaleyre, J.; Broyer, M. Chem. Phys. Lett. 1993, 206, 521.

(2) Vezin, B.; Dugourd, Ph.; Bordas, C.; Rayane, D.; Broyer, M.; Vonacic Koutecky, V.; Pittner, J.; Fuchs, C.; Gauss, J.; Koutecky, J. J. Chem. Phys. 1995, 102, 2727.

(3) Bonacic Koutecky, V.; Pittner, J.; Koutecky, J. Chem Phys. 1996, $210,313$.

(4) Rao, B. K.; Khanna, S. N.; Jena, P. Phys. Rev. B 1991, 43, 1416.

(5) Fuentealba, P.; Reyes, O. J. Phys. Chem. A 1999, 103, 1376.

(6) Becke, A. D.; Edgecombe, K. E. J. Chem. Phys. 1990, 92, 5397.

(7) Savin, A.; Jepsen, O.; Flad, J.; Andersen, O. K.; Preuss, H.; von Schnering, H. Angew. Chem., Int. Ed. Engl. 1992, 31, 187. Savin, A.; Becke, A. D.; Flad, J.; Nesper, R.; Preuss, H.; von Schnering, H. Angew. Chem., Int. Ed. Engl. 1991, 30, 409.
(8) Savin, A.; Nesper, R.; Wengert, S.; Fassler, T. Angew. Chem., Int. Ed. Engl. 1997, 36, 1808.

(9) Fuentealba, P.; Savin, A. J. Phys. Chem. A 2000, 104, 10882.

(10) Chamorro, E.; Santos, J. C.; Gomez, B.; Contreras, R.; Fuentealba, P. J. Chem. Phys. 2000, 114, 23.

(11) Berski, S.; Silvi, B.; Latajka, Z.; Leszczynski, J. J. Chem. Phys. 1999, 111, 2542 .

(12) Rousseau, R.; Marx, D. Chem. Eur. J. 2000, 6, 2982.

(13) Silvi, B.; Savin, A. Nature (London) 1994, 371, 683.

(14) Savin, A.; Silvi, B.; Colonna, F. Can. J. Chem. 1996, 74, 1088.

(15) Kohout, M.; Savin, A. J. Comput. Chem. 1997, 18, 1431.

(16) Fuentealba, P. Int. J. Quantum Chem. 1998, 69, 559.

(17) Becke, A. D. J. Chem. Phys. 1993 98, 5648.

(18) Frisch, M. J.; Trucks, G. W.; Schlegel, H. B.; Scuseria, G. E.; Robb, M. A.; Cheeseman, J. R.; Zakrzewski, V. G.; Montgomery, J. A., Jr.; Stratmann, R. E.; Burant, J. C.; Dapprich, S.; Millam, J. M.; Daniels, A. D.; Kudin, K. N.; Strain, M. C.; Farkas, O.; Tomasi, J.; Barone, V.; Cossi, M.; Cammi, R.; Mennucci, B.; Pomelli, C.; Adamo, C.; Clifford, S.; Ochterski, J.; Petersson, G. A.; Ayala, P. Y.; Cui, Q.; Morokuma, K.; Malick, D. K.; Rabuck, A. D.; Raghavachari, K.; Foresman, J. B.; Cioslowski, J.; Ortiz, J. V.; Stefanov, B. B.; Liu, G.; Liashenko, A.; Piskorz, P.; Komaromi, I.; Gomperts, R.; Martin, R. L.; Fox, D. J.; Keith, T.; Al-Laham, M. A.; Peng, C. Y.; Nanayakkara, A.; Gonzalez, C.; Challacombe, M.; Gill, P. M. W.; Johnson, B. G.; Chen, W.; Wong, M. W.; Andres, J. L.; Head-Gordon, M.; Replogle, E. S.; Pople, J. A. Gaussian 98, revision A.7; Gaussian, Inc.: Pittsburgh, PA, 1998.

(19) Nouri S.; Krokidis X.; Fuster F.; Silvi B. TopMod package, Université Pierre et Marie Curie, 1997, http://www.lct.jussieu.fr; Comput. Chem. (Oxford) 1999, 23, 597.

(20) Hibbard, B.; Kellum, J.; Paul, B. Vis5d 5.1, Visualization Project. University of Wisconsin. Space Science and Engineering Center. Hibbard, B., Santek, D. Proc. IEEE Visualization 1990, 90, 129.

(21) The Cartesian coordinates of all clusters can be obtained from the author (P.F.) upon request.

(22) Jones, R. O.; Lichtenstein, A.; Hutter, J. J. Chem. Phys. 1997, 106, 4566.

(23) Bader, R. Atoms in Molecules. A Quantum Theory, Oxford Science Publication: Oxford, U.K., 1990.

(24) Antoine, R.; Dugourd, Ph.; Rayane, D.; Benichou, E.; Vezin, B.; Broyer, M. Z. Phys. D 1997, 40, 436. 